Results All 13 patients had underlying diseases, 12 had been treating with immunosuppressive drugs, except one case who had underlying OA. SLE was the most common underlying disease found in our study. Acute and chronic onset monoarthritis occurred in a similar numbers. Chronic long standing joint infection mostly occurred in the patients with partial response to the first line antibiotic treatment. Knee and hip joint were the common sites of infection. Arthroscopic drainage or arthrotomy was performed in all but one patient who was treated by repeated arthrocentesis of the knee joint. All patients received at least 2week parenteral antibiotic. Three patients were excluded from antibiotic treatment evaluation because of lost follow up after being discharged from the hospital.

Clinical response at the early phase: In 16 events of Salmonella septic arthritis, 6 were treated with cotrimoxazole, 7 with quinolone compound and 3 with beta-lactam antibiotics. Dramatic clinical response was found only in the patients who were treated with cotrimoxazole or quinolone compound antibiotics. 2 out of 3 patients who were treated with beta lactam antibiotics partially responded to antibiotics given. After 8 weeks, these 2 patients were retreated with another course of cortimoxazole or quinolone compound.

Long term Clinical outcome: In all patients who were treated with 3 month course of quinolone compound, there was no relapse after 1-5 years follow up. Relapses were more common in cotrimoxazole treatment group (4 out of 6) and usually occurred within 4 months after antibiotic was stopped. Only one case was completely responded to beta-lactam antibiotic treatment without relapse. AVN was the most common complication found in Salmonella septic hip, and chronic osteomyelitis was found in a case with septic knee.

Conclusion We suggest to treat Salmonella septic arthritis in immunocompromised host with adequate drainage and 3 months of quinolone compound antibiotics. Alternative regimen is parenteral cotrimoxazole in an early phase followed by oral quinolone compound for totally 3 months. Long term treatment with cotrimoxazole frequently resulted in relapse.

\section{SAT0221 DIAGNOSTIC VALUE OF SERUM AND SYNOVIAL PROCALCITONIN (PCT) IN BACTERIAL, CRYSTAL- ASSOCIATED AND RHEUMATOID ARTHRITIS}

${ }^{1} \mathrm{~J}$ Sibilia, ${ }^{1} \mathrm{M}$ Martinot, ${ }^{2} \mathrm{~A}$ Saraux, ${ }^{2} \mathrm{P}$ Guggenbuhl, ${ }^{2} \mathrm{X}$ Puechal, ${ }^{2} \mathrm{JF}$ Maillefert, ${ }^{2} \mathrm{M}$ Soubrier, ${ }^{2} \mathrm{G}$ Coumaros, ${ }^{1} \mathrm{~F}$ Liote, ${ }^{1} \mathrm{FX}$ Limbach. ${ }^{1}$ Rheumatology: ${ }^{2}$ Groupe $d^{\prime}$ Etude Procalcitonine, CHU Hautepierre, Strasbourg, France

10.1136/annrheumdis-2001.724

Background Procalcitonin (PCT), the calcitonin peptide precursor, is a new specific marker of severe bacterial and fungal infections. PCT is not or slightly elevated in others inflammatory diseases. PCT measurements could help to differentiate bacterial arthritis to other forms of acute arthritis.

Objectives To determine the interest of serum and synovial PCTfor the diagnosis of acute bacterial arthritis.

\section{Methods}

- A one year prospective study (RR study group): sera and synovial fluid from 32 adults with acute arthritis were immediately frozen $\left(-20^{\circ} \mathrm{C}\right)$ before treatment. for all patients, the diagnosis was confirmed by specific synovial analysis.

- PCT $(\mathrm{N}<0.5 \mathrm{mg})$ was measured by a specific and ultrasensitive immunoluminometric yesy (BRAHMS diagnostica, Berlin, Ger.)

Results

\begin{tabular}{|c|c|c|c|c|}
\hline & $\begin{array}{l}\text { serum PCT ng/ } \\
\mathrm{ml}\end{array}$ & $\begin{array}{l}\text { synovial PCT } \\
\mathrm{ng} / \mathrm{ml}\end{array}$ & CRP mg/l & ESR mm/h \\
\hline $\begin{array}{l}\text { Bacterial arthritis }(n= \\
\text { 10) }\end{array}$ & $\begin{array}{l}0.59(<0.08- \\
7.91)\end{array}$ & $0.22(0-1.31)$ & $\begin{array}{l}37(61- \\
493)\end{array}$ & $80(30-120)$ \\
\hline $\begin{array}{l}\text { Crystal arthritis }(n= \\
\text { 11) }\end{array}$ & $\begin{array}{l}<0.08^{* *}(<0.08- \\
0.69)\end{array}$ & $\begin{array}{l}0.12 \text { (NS) }(0.08- \\
0.88)\end{array}$ & $91^{*}(4-355)$ & $\begin{array}{l}42 \text { (NS) (3- } \\
98)\end{array}$ \\
\hline $\begin{array}{l}\text { Rheumatoid arthritis } \\
(\mathrm{n}=11)\end{array}$ & $\begin{array}{l}<0.08^{* *}(<0.08- \\
0.61)\end{array}$ & $<0.08-0.6)$ & $\begin{array}{l}50.4^{* *} \\
(3.2-90)\end{array}$ & $\begin{array}{l}50 \text { (NS) (9- } \\
130)\end{array}$ \\
\hline
\end{tabular}

Results are expressed in median and range. Values are compared between septic group and crystal or rheumatoid group by MannWhitney test: * ${ }^{*} \mathrm{p}<0.01 ;$; $\mathrm{p}<0.05$.

Conclusion

- These results show that plasma PCT levels are higher in patients with septic arthritis, but PCT sensitivity remains unsufficient. However, in case of bacterial arthritis, PCT in association with CRP, could be of great interest for clinicians, as its increase is in favour of a bacterial origin.

- PCT is not present in all biological fluids. If synovial PCT does not seem to be helpful in clinical diagnosis, this study is, to our knowledge, the first to demonstrate PCT existence in synovial fluid.

\section{SAT0222 TOTAL BODY AND REGIONAL BONE MINERAL AND SOFT-TISSUE COMPOSITION IN HIV DISEASE}

${ }^{1} \mathrm{~J}$ Bernard, ${ }^{2} \mathrm{E}$ Bonnet, ${ }^{2} \mathrm{C}$ Acquilina, ${ }^{2} \mathrm{R}$ Hervé, ${ }^{2} \mathrm{P}$ Massip, ${ }^{1} \mathrm{~B}$ Mazières. ${ }^{1}$ Department of Rheumatology; ${ }^{2}$ Department of Infectiology, University Hospital of Toulouse, Toulouse, France

\subsection{6/annrheumdis-2001.725}

Background Osteopenia and adipose tissue maldistribution are two complications of highly active anti-retroviral therapy (HAART: 1 protease inhibitor +2 nucleoside reverse transcriptase inhibitors). Dual energy x-rays absorptiometry (DEXA) is a reliable tool to assess total body and regional bone mineral and soft-tissue composition.

Objectives (1) To compare the results of DEXA in HIV-infected patients treated or not with HAART, with or without clinical lipodystrophy and (2) to evaluate DEXA as a tool for early diagnosis of body fat redistribution.

Methods A cross-sectional analysis was performed on 220 men. All subjects gave written informed consent. Controls (C): 106 healthy uninfected volunteers without medical or surgical history, nor immobilisation and therapies which may modify bone mineral density, mean age 38 years. One hundred and fourteen HIV-infected patients at steady-state, without opportunist disease, nor prophylactic drugs? use were divided in 3 groups: (i) 20 naive HIV-patients (N: mean age 38 years, disease duration 43 mths, viral load $3.7 \mathrm{log}, \mathrm{CD}^{+} 417 / \mathrm{mm}^{3}$ ), (ii) $32 \mathrm{HIV}$-treated patients with no clinical lipodystrophy (n-CLD: mean age 35, disease duration $72 \mathrm{mths}$, HAART duration $15 \mathrm{mths}$, viral load $2.3 \mathrm{log}, \mathrm{CD}^{+} 524 / \mathrm{mm}^{3}$ ), and (iii) $62 \mathrm{HIV}$-treated patients with clinical lipodystrophy (CLD: mean age 42, disease duration 94 mths, HAART duration 26 mths, viral load $1.8 \mathrm{log}, \mathrm{CD}^{+} 483$ / $\mathrm{mm}^{3}$ ). Total body and regional soft-tissue composition were measured with DEXA (DPX-L, Lunar Corp. Acquisition and analysis software 4.6). The following parameters were studied: 
Fat Mass\% (FM,\%), Lean Mass (LM, kg), Bone Mineral Content (BMC, mg), and Fat Mass Index (FMI: trunk fat mass/legs fat mass). Statistics. Mean \pm SD, ANOVA, Scheffe's F procedure for post-hoc comparison.

Results Lean Mass was the same in the 4 groups. Despite 43 months of disease duration, Naive and Controls had the same fat mass, BMC and FMI. The two treated HIV-infected groups had lower Fat Mass and upper Fat Mass Index than Controls. Loss in Fat Mass at the expense of the legs was proportional to duration of HAART. The great variability of the FMI (SD) in these two groups suggested a poor clinical sensitivity to change. Decrease of BMC seemed treatment-dependent. Lipodystrophy appeared also age-related.

\begin{tabular}{|c|c|c|c|c|c|}
\hline & BMI & BMC & $\begin{array}{l}\text { Lean } \\
\text { mass }\end{array}$ & $\begin{array}{l}\text { Fat } \\
\text { mass }\end{array}$ & Fat mass index \\
\hline Controls (1) & 25 & 3197 & 58.7 & 16.1 & $2.04 \pm 0.43$ \\
\hline Naive (2) & 25 & 3061 & 61.2 & 12.4 & $2.07 \pm 0.38$ \\
\hline n-CLD (3) & 23 & 2859 & 58.8 & 9.8 & $2.49 \pm 0.90$ \\
\hline CLD (4) & 23 & 2700 & 57.6 & 9.3 & $3.46 \pm 1.10$ \\
\hline ANOVA & $\begin{array}{l}\mathrm{P}< \\
0.05\end{array}$ & $P<0.05$ & n.s. & $P<0.05$ & $P<0.05$ \\
\hline $\begin{array}{l}\text { Scheffe }(P< \\
0.05)\end{array}$ & $\begin{array}{l}1-4,2- \\
4\end{array}$ & $\begin{array}{l}1-3,1-4,2- \\
4\end{array}$ & n.s. & $1-3,1-4$ & $\begin{array}{l}1-3,1-4,2-4,3- \\
4\end{array}$ \\
\hline
\end{tabular}

Conclusion DEXA allows an early diagnosis of fat maldistribution. We propose to perform this exam to all HIV-infected patients once a year before treatment and every 6 months in patients under treatment.

\section{SAT0223 LYME MENINGORADICULITIS IN AN ENDEMIC ZONE: CLINICAL SIGNS}

${ }^{1} \mathrm{~F}$ Roux, ${ }^{2} \mathrm{~L}$ Artru, ${ }^{2} \mathrm{~B}$ Haettich, ${ }^{2} \mathrm{~J}$ Esparbes, ${ }^{2} \mathrm{X}$ Puéchal. ${ }^{1}$ Rheumatology, Hospital Bichat, Paris; ${ }^{2}$ Rheumatology, Le Mans General Hospital, Le Mans, France

\subsection{6/annrheumdis-2001.726}

Background Neuroborreliosis has been called "the new great imitator".

Objectives The aim of this study was to define the symptoms of meningoradiculitis.

Methods We collected prospective data from all patients admitted to hospital with Lyme meningoradiculitis between June 1st, 1998 and December 31st, 1999 in an endemic zone located in western France. Diagnosis was based on lymphocytic meningitis associated with either intrathecal specific antibody synthesis or high serum titers of specific IgM in ELISA and western Blot analysis.

Results Eleven patients ( 9 women, 2 men), with a mean age of 62 years (range: 37 to 87 ) were included during the study period. Two thirds of these patients were admitted to rheumatology wards during the summer. The onset of symptoms was preceded, 5 to 60 days earlier, by a tick bite in $64 \%$ of cases or erythema migrans in $55 \%$ of cases. In $18 \%$ of patients, neither a tick bite nor erythema was observed. Non specific symptoms were recorded in $82 \%$ of cases, with transient fever or flu syndrome in $45 \%$ of all cases. Cervical radiculoneuritis was observed in 4 cases, symptoms affecting several nerve roots of the lower limbs in 3 cases, femoral neuropathy in 2 cases, a bilateral sensory radiculoneuritis T11-12 in one case and poorly localised paresthesias in the lower limbs in one case. The meningeal signs and symptoms were minimal or, more frequently, absent. A peripheral motor paresis was observed in one quarter of the cases, but without Bell's palsy or encephalic or medullary signs. In half the patients, there was associated spinal pain not relieved by rest. All patients reported nocturnal exacerbation in pain. The electrocardiographic abnormalities included firstdegree atrioventricular block in 2 patients. The course of the disease was consistently favourable on ceftriaxone IV treatment, with rapid effective relief of pain.

Conclusion A diagnosis of Lyme meningoradiculitis should be considered in endemic zones in all cases of spine pain and/or radiculitis with nocturnal exacerbation, especially in the summer period.

\section{SAT0224 PERIPHERAL NERVE INVOLVEMENT IN HCV-INFECTED PATIENTS WITH AND WITHOUT MIXED CRYOGLOBULINEMIA}

${ }^{1} S$ Sampaolo, ${ }^{2} \mathrm{~L}$ Ambrosone, ${ }^{1} \mathrm{G}$ Sanges, ${ }^{1} \mathrm{~L}$ De Martino, ${ }^{2} \mathrm{~S}$ Migliaresi, ${ }^{1} \mathrm{G}$ Di lorio, ${ }^{2} \mathrm{G}$ Valentini. ${ }^{1}$ Neurology Unit; ${ }^{2}$ Rheumatology Unit, Second University of Naples, Naples, Italy

10.1136/annrheumdis-2001.727

Background In contrast to cutaneous vasculitis, the morphology of which is well known, that of peripheral nerve lesions in HCV-positive mixed cryoglobulinemia (MC) patients are still under debate. ${ }^{1,2}$

Objectives To evaluate the pathological processes underlying the peripheral nerve damage in HCV-infected patients, with and without MC.

Methods From $14 \mathrm{HCV}$-infected patients (10 with MC and 4 without), all with clinically peripheral neuropathy, a sural nerve biopsy was obtained. Diseases other than HCV infection were excluded. The tissue samples were processed according to standard methods to perform morphologic and morphometric evaluation, on light and electronmicroscopic study. An immunohistochemical evaluation was carried out using labelled antisera against immunoglobulins (IgA, IgG, IgM), complement proteins (C1q, C3, terminal complex C5-9), and cellular antigens (CD3, CD11a-b-c, CD20, CD45, CD68).

Results In all nerve biopsies an axonal involvement without a distinctive vasculitis was found. Scarce perivascular infiltration by monuclear cells was observed, particularly around perineural blood vessels; extravasation of red cells was also found in the endoneurial vessels. Immunohistochemical study pointed out deposits of immunoglobulins and complement in sub-perineurial vessels, and infiltrations by mononuclear cells, mainly macrophages and CD4 $\mathrm{T}$ cells. Demyelinating neuropathy was only observed in patients without MC.

Conclusion Our data suggest that in $\mathrm{HCV}$-infected patients different physiopathological processes are involved in induction of peripheral nerve damage. A potential direct pathogenic role of HCV should be investigated.

\section{REFERENCES}

1 Bonetti B et al. J Neuroimmunol. 1997:73:145

2 Bonetti B, et al. Virchows Arch. 1999;434:533 